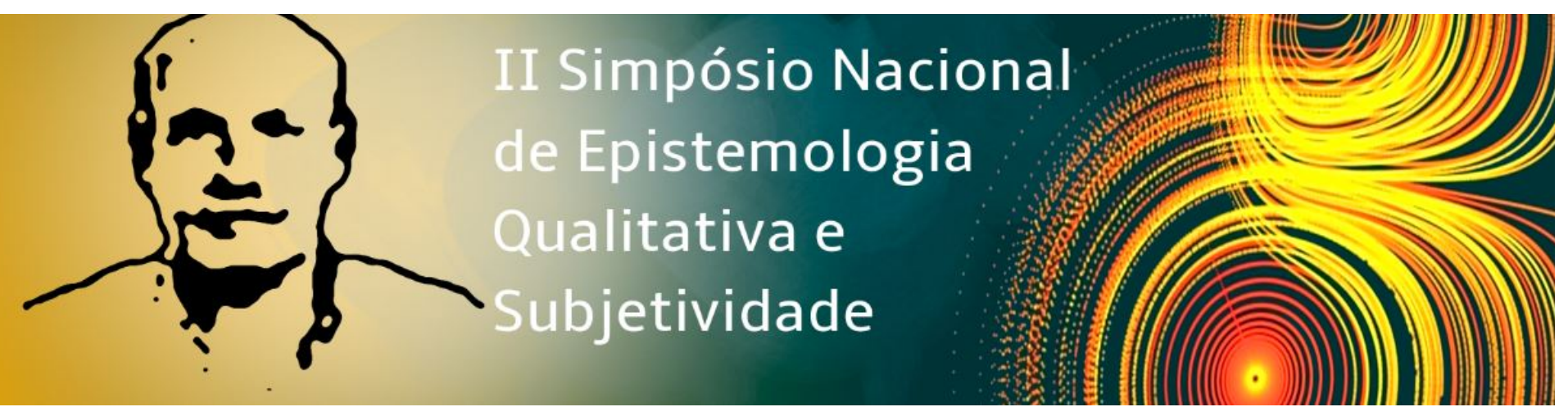

Eixo temático: 7. O trabalho pedagógico e a didática desde a perspectiva da subjetividade;

\title{
A criança como sujeito que aprende matemática
}

Amanda Marina Andrade Medeiros, Universidade de Brasília, amandamedeiros@unb.br

\section{Resumo}

Observamos que os atuais conceitos e definições de aprendizagem matemática estão intimamente relacionados aos processos cognitivos dos alunos, nos quais as análises científicas, em sua maioria, excluem dessa dinâmica as emoções produzidas ou exteriorizadas na aprendizagem matemática. Por isso destacamos a necessidade de trabalhos que analisem o sujeito de forma integral, considerando todos os aspectos subjetivos que constituem o ato de aprender. $\mathrm{Na}$ área educacional ainda são poucos os trabalhos que têm como foco a subjetividade do indivíduo, em especial tratando-se de educação matemática, a maior parte estão relacionados às metodologias de ensino, currículo, avaliação, políticas públicas e aspectos sociais da educação. Já na área de psicologia da educação os trabalhos com foco cognitivista se apresentam em número bem maior do que aqueles relacionados às emoções e à subjetividade. Quando falamos em aprendizagem matemática devemos destacar aspectos que estão muito além do operacional, do cognitivo, pois os sentidos subjetivos que emergem no ato de aprender ultrapassam os muros da escola. Assim, enxergamos a aprendizagem matemática como um processo complexo e sistêmico. Nessa perspectiva o presente trabalho traz uma reflexão sobre o sujeito que aprende matemática, trazendo questionamentos referentes às metodologias que podem favorecer ou não o processo de construção do conhecimento matemático.

Palavras chave: Educação matemática, sujeito que aprende, didática. 


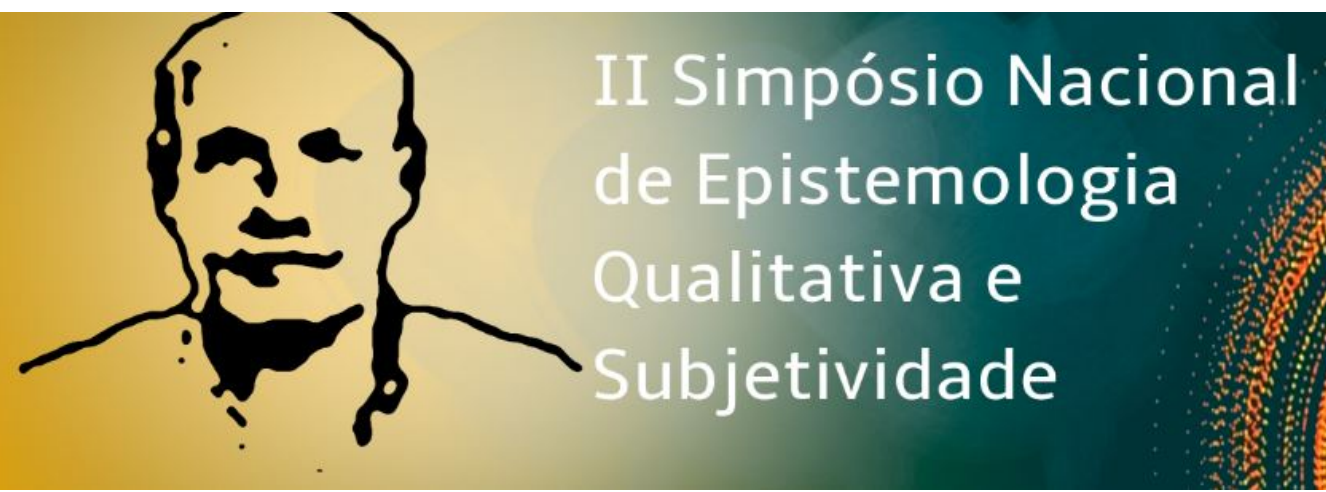

O ensino e a aprendizagem têm sido alvo de muitos estudos, que tentam compreender as falhas no ensino, as diversas didáticas que facilitam ou dificultam a aprendizagem, os alunos e suas dificuldades cognitivas, as metodologias eficazes no processo de ensinoaprendizagem (MEDEIROS, 2016). No entanto, o que se apresenta como pano de fundo epistemológico desta tentativa é a própria complexidade dos processos de aprendizagem, de construção de conceitos e procedimentos pelo sujeito epistêmico, em especial a construção e aprendizagem de conceitos matemáticos dentro e fora da escola.

Porém, os estudos que enxergam a criança como um ser complexo, histórico, cognitivo e emocional ainda estão ganhando espaço nas pesquisas atuais. Durante muito tempo os estudos sobre aprendizagem tiveram como foco os aspectos cognitivos e intelectuais, minimizando a importância dos aspectos subjetivos, incluindo, aqui, os aspectos emocionais. A escola atual, em grande parte, prioriza os aspectos cognitivos e memorísticos, dando ênfase à transmissão e não à construção de conhecimento. Conhecimento este que a escola impõe como verdadeiro, impedindo, assim, o desenvolvimento de processos e aprendizagens compreensivas e criativas (MITJÁNS MARTÍNEZ; GONZÁLEZ REY, 2017). Enfatizamos, assim, a relevância da categoria sujeito na perspectiva de González Rey e Mitjáns Martínez (2017, p.72), que define como

\begin{abstract}
um indivíduo ou grupo com capacidade de se posicionar, de gerar com seus posicionamentos, processos que estão para além de seu controle e de sua consciência. É um indivíduo configurado subjetivamente, que gera sentidos subjetivos para além de suas representações, mas que, ao mesmo tempo, toma decisões, assume posicionamentos, tem produções intelectuais e compromissos, que são fontes de sentidos subjetivos e abrem novos processos de subjetivação.
\end{abstract}

Nos sistemas de ensino, tanto em termos de currículo como de formação de professores, o conhecimento matemático é imposto como um conjunto de verdades construídas e instituídas, onde aprender, tanto na perspectiva individual quanto social, sintetiza-se, em geral, pela assimilação passiva dos conhecimentos institucionalizados, com pouca perspectiva de assumir a criança como sujeito produtor de sentidos subjetivos no complexo processo da aprendizagem matemática. A tônica pedagógica é da reprodução mecânica de procedimentos algorítmicos com pouca chance de desenvolvimento de pensamento crítico, estético e criativo por parte daquele que se engaja no processo do 


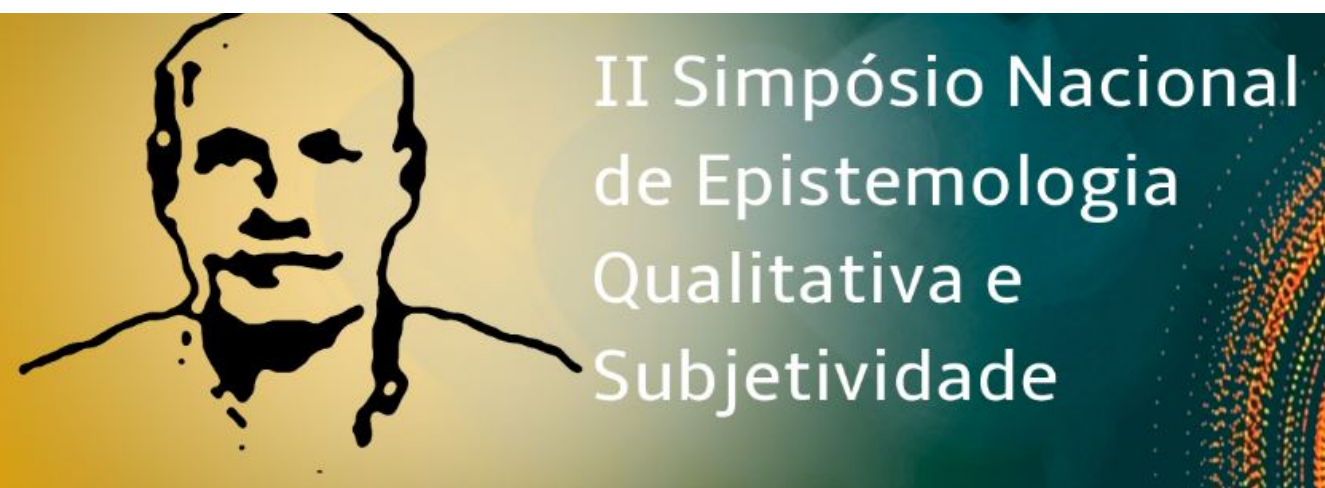

aprender matemática. Afinal, aprender matemática, para maioria, é seguir regras rígidas, imutáveis, muitas vezes desprovidas de significados, cabendo à aprendizagem a assimilação de ritos metodológicos e linguísticos de pouca contribuição para a formação de um cidadão crítico e criativo, pois a tônica é da reprodução.

Destacamos, em contrapartida, apoiada na perspectiva teórica e epistemológica de Fernando González Rey, o caráter ativo da criança, tanto como indivíduo de ação, incluindo ação para aprendizagem, mas também como um agente dinâmico dentro do espaço da sua subjetividade, produtor de sentidos subjetivos, em especial, no aprender matemático.

Podemos estabelecer, então, que a categoria sujeito implica ação. Quando falamos da importância da ação do indivíduo em seu processo de aprendizagem, devemos resgatar a criança como sujeito. Podemos então falar do sujeito que aprende. Um ser ativo no seu processo de aprendizagem.

É importante destacar que não é apenas a ação da criança sobre o objeto de conhecimento que gera aprendizagem, mas os sentidos subjetivos que são produzidos nesse processo, como destaca González Rey (2006), a criança aprende não só com o intelecto, mas também com emoções, advindas de diferentes vivências.

É indispensável pensar o sujeito que aprende a partir do conceito de sentido-subjetivo, constituído pela unidade simbólico-emocional (GONZÁLEZ REY, 2006). O conceito de sujeito implica a produção de sentidos subjetivos, no qual o "sujeito representa a capacidade de posicionamento de indivíduos e grupos, cujos limites estão na própria produção simbólica da cultura e nos recursos subjetivos" (GONZÁLEZ REY; MITJÁNS MARTÍNEZ, 2017, p.73), que envolve os recursos emocionais.

Trabalhando na perspectiva da subjetividade, podemos dizer que para haver aprendizagem compreensiva ou criativa é necessário pensar o indivíduo como sujeito, pois este implica ação no seu meio, incluindo a aprendizagem, já que "as funções tradicionalmente definidas como intelectuais se tornam subjetivas quando o indivíduo emerge como sujeito ou agente da experiência, única condição em que ele é capaz de gerar sentidos subjetivos vivendo essa experiência” (GONZÁLEZ REY; MITJÁNS MARTÍNEZ, 2017, p.76). Além disso essa ação do sujeito no espaço social, que é também cultural, depende da sua subjetividade, constituída ao longo da sua história de vida, ou seja, as experiências do sujeito dentro de 


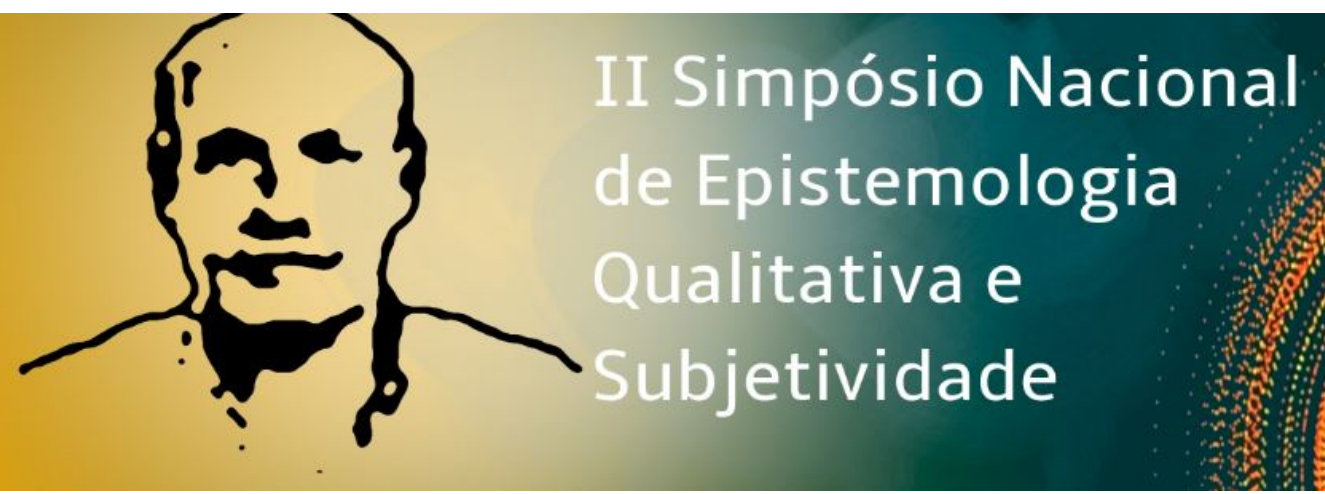

diversos espaços sociais. Um sujeito na sua inteireza, na sua complexidade, na sua incompletude, na sua perspectiva de desejos e frustrações, de sonhos e de realidade.

Para González Rey (2005a, p. 223), “subjetividade é a forma complexa em que o psicológico funciona nos indivíduos, cultural e historicamente constituídos e nos espaços sociais de suas práticas e modos de vida”. Assim, destacamos a importância da singularidade do indivíduo no processo de aprendizagem. O sujeito que aprende é único em sua subjetividade, logo os processos que levam à aprendizagem também são únicos. Os sentidos subjetivos mobilizados no processo de aprendizagem, que permitem a expressão de configurações subjetivas que levarão à ação do sujeito, são únicos. São muitas as emoções que surgem no processo de aprendizagem do sujeito. Como destaca González Rey (2006):

as emoções que no processo de aprendizagem estão associadas não apenas com o que ele vivencia como resultado das experiências implicadas no aprender, mas emoções que têm sua origem em sentidos subjetivos muito diferentes, que trazem ao momento atual do aprender momentos de subjetivação produzidos em outros espaços e momentos da vida (GONZÁLEZ REY, 2006, p. 34).

Nessa perspectiva, podemos nos perguntar se o foco de compreensão das aprendizagens e das dificuldades deve estar nas técnicas e metodologias ou nos sujeitos de aprendizagem? Será que as dificuldades de aprendizagem decorrem exclusivamente das metodologias ou dos sentidos subjetivos que a criança produz em sua ação? Será que o foco do estudo das dificuldades de aprendizagem deve estar nas metodologias ou na unidade simbólico-emocional que essas geram na criança em processo de aprendizagem?

Nesse contexto, destacamos, também, o conceito de "ser matemático" desenvolvido por Muniz (2015, p.15). Para o autor

\begin{abstract}
o conceito de "ser matemático" considera o sujeito que aprende como efetivamente produtor de conhecimentos e saberes matemáticos, dentro ou fora da escola, em situação de sucesso ou de fracasso escolar. Essa perspectiva epistemológica reconhece que a aprendizagem e a construção de saberes matemáticos não são lineares, tampouco isentas de erros. (...) A capacidade de todos para a realização de aprendizagens, de produção de modus de aprender e gerar saberes e conhecimentos, de comunicar e validar suas produções e verdades, nos mais diferentes campos do conhecimento humano e, em especial, na matemática é um dos fundamentos na proposição dessa categoria.
\end{abstract}

Para Muniz (2015), toda criança é um ser matemático que produz conhecimento. É na ação da criança com o objeto de conhecimento que esta aprende compreensivamente, produz 


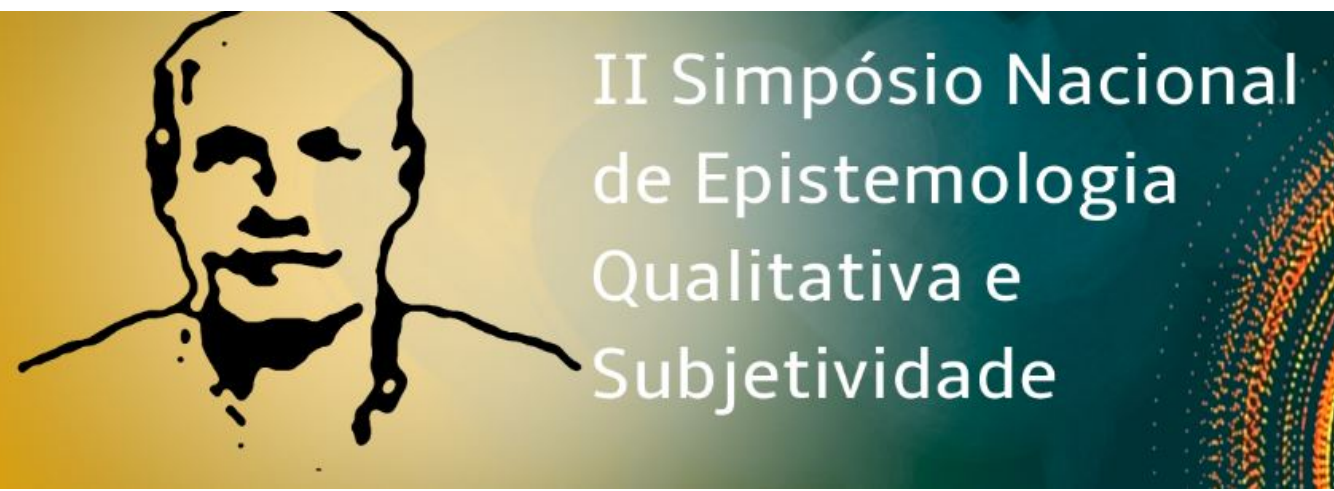

saberes e conhecimentos. Fazer matemática não é um dom, mas uma produção da criança em interação com os espaços em que vive. O ser matemático é ativo no seu processo de aprendizagem, logo o ser matemático é sujeito que aprende matemática (MUNIZ, 2015).

As crenças e concepções culturalmente relacionadas à matemática são únicas e diversas das presentes em outras áreas do conhecimento, logo a aprendizagem matemática se difere de outras aprendizagens, assim como a língua portuguesa se difere da história, da geografia, das artes, assim como os processos de aprender matemática se diferem de uma criança para outra: não há um padrão para o complexo processo de aprender matemática que garanta qualidade de ensino universal e invariante, pois a experiência é de cada um que aprende, os processos de aprender, de produção simbólico-emocional, estão relacionados com a vida de cada indivíduo que aprende e o que estas experiências operam na psique de cada um.

A matemática é culturalmente vista como uma área do conhecimento destinada aos mais inteligentes, aos privilegiados, que nasceram com o dom de calcular. Os conhecimentos culturalmente concebidos como difíceis de aprender estão relacionados com o conhecimento matemático (KAMII, 2005). Tais ideias sobre a matemática geram, muitas vezes, emoções negativas em relação a esse conhecimento (DAL VESCO, 2002). As crenças que permeiam o conhecimento matemático trazem para o momento do aprender sentidos subjetivos construídos dentro dessa cultura, trazendo ideias e emoções negativas em relação a esse conhecimento, levando muitos a acreditarem na sua não capacidade em aprender matemática, negando a se reconhecer como ser matemático, o que é mais grave quando este sujeito é uma criança em importante momento de seu desenvolvimento e na construção da imagem de si mesmo como sujeito capaz ou não de aprender. A configuração subjetiva produzida no processo de aprendizagem é constituída pelos sentidos subjetivos construídos pela criança ao longo de sua história de vida, que está permeada por tais crenças e concepções sobre o conhecimento matemático, influenciando, assim, o processo de aprendizagem.

Podemos destacar, também, as metodologias utilizadas no processo de aprendizagem matemática, que influenciam fortemente os sentidos subjetivos produzidos nesse processo, como podemos verificar na fala de uma das participantes da pesquisa de Medeiros (2012, p. $3000)$. 


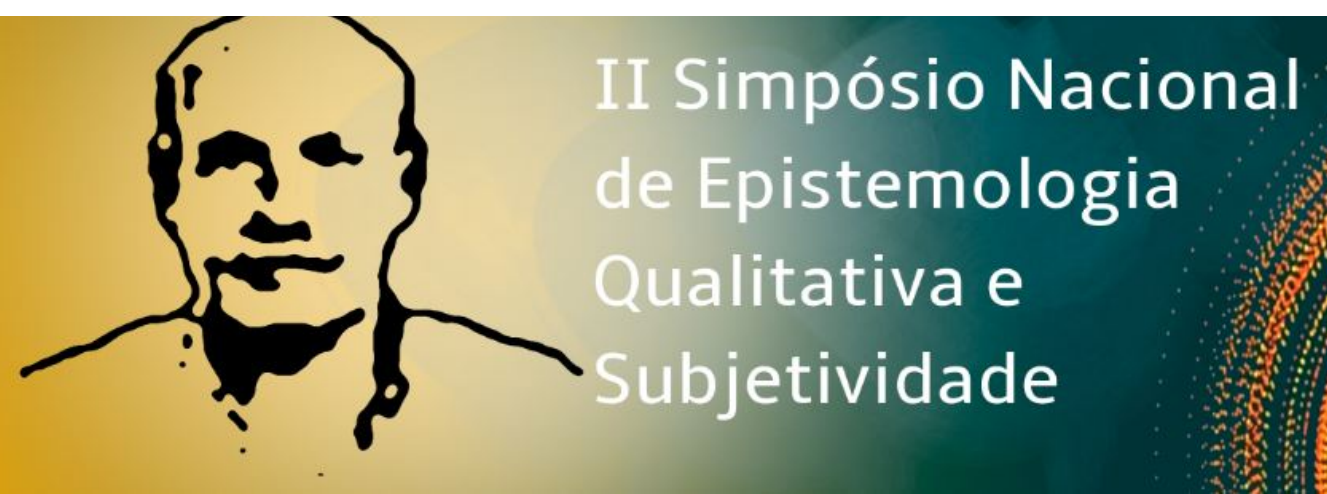

Mas sempre fui fraca em Matemática, teve uma vez na $3^{\mathrm{a}}$ série, em Guanambi, que minha professora estava tomando tabuada de multiplicação do número 5 , aí eu acertei, mas quando perguntou a de 6 não consegui dar conta do recado e levei 10 palmadas nas mãos que ficaram vermelhas e ardendo. Quando eu errei a tabuada a professora me colocou no canto da sala e só saí de lá na hora de ir embora. [...] Outra vez eu estava cursando a $8^{\mathrm{a}}$ série, meu professor deu uma prova surpresa, sobre raízes cúbicas, e fiquei tão nervosa que me deu uma crise de falta de ar, uma tremedeira, que quando o professor viu minha situação deixou a minha prova para fazer no outro dia.

Aqui observamos que a metodologia utilizada pela professora, com ênfase na punição, gerou emoções de aversão à matemática, onde, mesmo em um ambiente de não punição, seu corpo exteriorizava emoções de medo e aversão ao conhecimento matemático, emoções negativas. Aqui destaca-se a metodologia utilizada no processo de ensino de matemática como favorecedora de produção de sentidos subjetivos que se relacionam especificamente com o aprender e fazer matemática.

Destacamos, assim, a importância das categorias "o sujeito que aprende" e "ser matemático". O sujeito que aprende matemática tem uma subjetividade única, é ativo no seu processo de aprendizagem matemática, participa do seu meio social modificando-o e sendo modificado por ele e é produtor de sentidos subjetivos implicados no ato de aprender. Em especial a matemática e sua aprendizagem como possibilidade de reconhecer o diferente, a diversidade, no aprender, no pensar, no sentir e no emocionar-se na relação com os objetos matemáticos.

\section{O conhecimento e a aprendizagem escolar}

As experiências vivenciadas no ambiente escolar geralmente diferem do tipo de experiência vivenciada no âmbito pessoal, tanto pelas características do conhecimento, como pelas metodologias empregadas, como destacou Brousseau (2010) em sua Teoria das Situações. Nessa perspectiva, podemos refletir sobre os processos envolvidos no ato de aprender nesses dois contextos, escolar e cotidiano.

Algumas investigações iniciais de Vigotski (1995, 2009b), levam-no a compreender que a aprendizagem de conceitos escolares se dá de forma diferente da aprendizagem de conceitos cotidianos (VIGOTSKI, 1995), incluindo diferenciações afetivas, como a motivação para o 


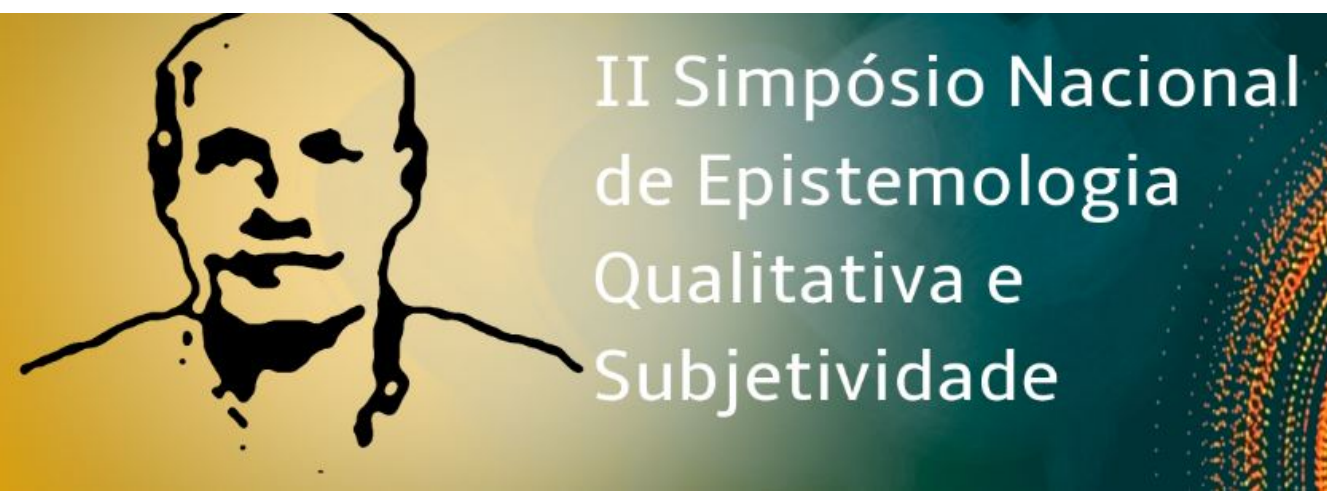

aprender. Para o estudioso, os conceitos constituídos no processo de aprendizagem escolar ocorrem por via diferente que no processo de experiência cotidiana da criança.

Os conceitos científicos, que se formam no processo de aprendizagem, distinguemse dos espontâneos por outro tipo de relação com a experiência da criança, outra relação sua com o objeto desses ou daqueles conceitos, e por outras vias que eles percorrem do momento da sua germinação ao momento da informação definitiva (VIGOTSKI, 2009b, p. 263).

Assim, em um primeiro momento, a aprendizagem de conceitos científicos, ou escolares, se dá de forma diferente da aprendizagem de conceitos espontâneos ou cotidianos, devido às características de cada um, devido às experiências proporcionadas em cada espaço social. Por exemplo, uma criança pode descrever e explicar o cálculo da área de um trapézio, demonstrando, assim, seu conhecimento sobre o conceito, porém, ao ser perguntada sobre o conceito de mãe, muitas vezes a explicação não é objetiva ou a criança não consegue explicar, porém o conceito de mãe está bem definido, devido às suas experiências pessoais e emocionais, além de suas reflexões sobre o conceito.

O conceito científico é definido historicamente por meio do desenvolvimento das ciências e posteriormente aprendido pelos indivíduos, diferente disso, o conceito cotidiano, como o de mãe, foi formado por meio das experiências do indivíduo com o ser mãe, seja essa experiência com sua própria mãe, ou com outras que fizeram parte de suas vivências, logo o conceito de mãe é diferente para cada pessoa, sendo determinado por suas experiências pessoais. Os conceitos espontâneos ou cotidianos manifestam emoções, incluindo motivações, diversas daquelas manifestadas na aprendizagem de conceitos científicos ou escolares. As experiências de uma criança no ambiente familiar são diferentes daquelas vivenciadas no ambiente escolar.

Por exemplo, no ambiente familiar, ou em outros ambientes informais, onde há aprendizagem, uma criança pode ter experiências riquíssimas, que a levam a aprender e a ter emoções positivas com o conhecimento aprendido. Essa mesma criança pode ter na escola experiências relacionadas ao castigo, à humilhação e à punição, levando-a a emoções negativas em relação ao conhecimento. Já outra criança pode ter experiências de humilhação e desvalorização na família, com castigos físicos e verbais, e na escola ter experiências positivas, de acolhimento e valorização. São inúmeras as possibilidades. Essas aprendizagens 


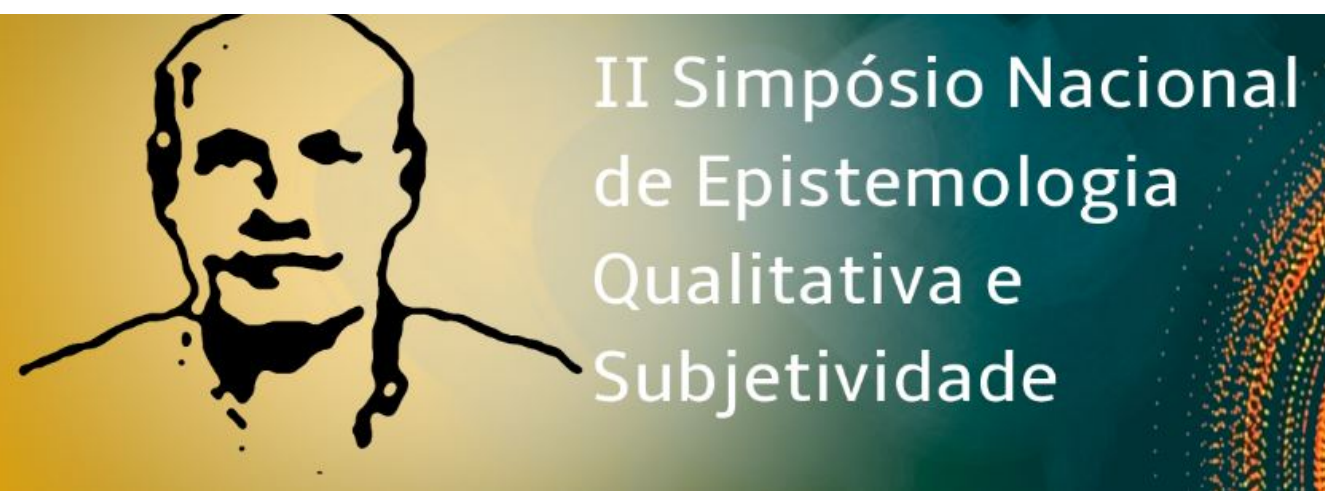

se diferenciam pela experiência proporcionada por cada uma, e é a experiência que permitirá a aprendizagem e definirá a qualidade dessa aprendizagem.

Para Vigotski (2010, p. 143),

A experiência e estudos mostraram que o fato emocionalmente colorido é lembrado com mais intensidade e solidez do que um fato indiferente. Sempre que comunicamos alguma coisa a algum aluno devemos procurar atingir seu sentimento. Isso se faz necessário não só como meio para melhor memorização e apreensão, mas também como objetivo em si.

Logo, é desejável que a aprendizagem escolar esteja ligada a emoções positivas, para suscitar no aluno o gosto e a vontade pelo fazer matemática. Porém, isso não significa que sentimentos negativos não favoreçam a produção de sentidos subjetivos que serão benéficos à aprendizagem, entretanto, muitas aprendizagens espontâneas estão ligadas a afetos positivos, logo elas se perpetuam e se tornam facilmente parte do sujeito, já aquelas vinculadas a emoções negativas, presente em muitas aprendizagens no espaço escolar, geram, por vezes, ansiedade, mal estar, estresse (DAL VESCO, 2002), muitas vezes impedindo a aprendizagem. Nessa perspectiva, Vigotski (2010, p. 319) destaca que

\footnotetext{
O professor deve se preocupar, sempre, não apenas em preparar as correspondentes forças de inteligência, mas também as correspondentes forças dos sentimentos. Não se esqueçam de estimular o sentimento do aluno cada vez que queiram que algo deixe raízes em sua mente. Com frequência dizemos: 'Recordo disso porque me surpreendeu na infância'.
}

Vigotski (2010) sugere que para que a aprendizagem seja perene e se constitua como parte do indivíduo é importante que esta esteja vinculada a processos emocionais positivos.

Fazemos esse paralelo entre a aprendizagem cotidiana e a aprendizagem escolar para revelar a importância das emoções no processo de aprendizagem, situação em que as aprendizagens que se relacionam com processos afetivos se tornam parte da subjetividade do sujeito, aproximando-se ao tipo de aprendizagem que consideramos desejável, aquela em que haja compreensão pelo indivíduo e que ele faça parte do processo. As emoções têm papel de extrema relevância no processo de aprendizagem, pois delas dependerão a qualidade da aprendizagem, pois a produção de sentidos subjetivos, essencial no processo de aprendizagem pelo sujeito, só é possível quando no processo de aprendizagem está envolvido processos emocionais, pois é a unidade simbólico-emocional que permitirá que a aprendizagem 


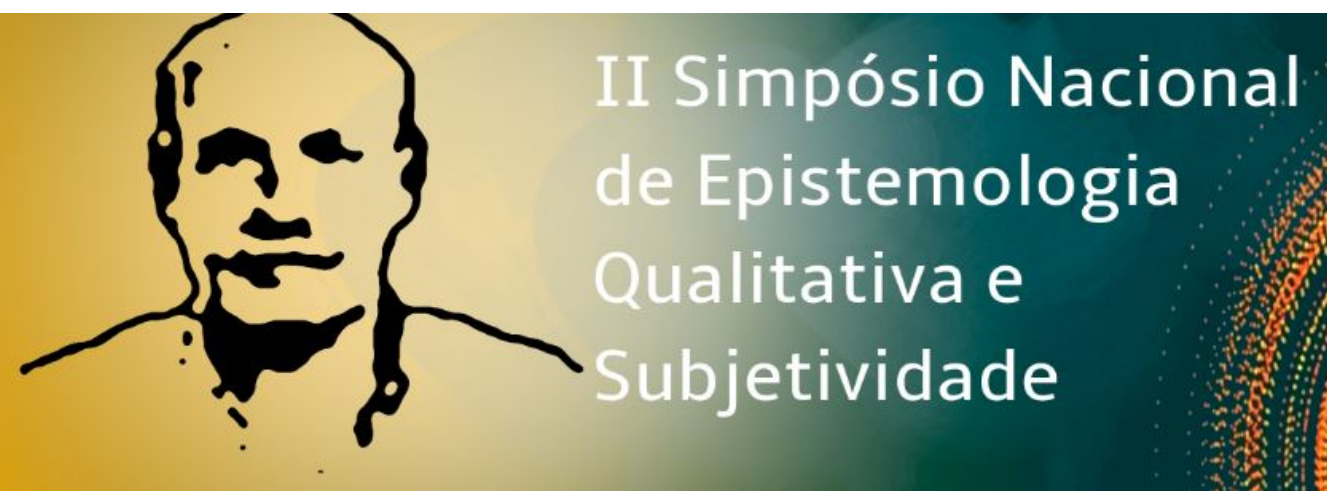

ultrapasse os processos operacionais e memorísticos e faça parte da subjetividade da criança.

Nessa perspectiva González Rey ( 2006, p. 39), destaca que

As emoções que permitem a emergência dos sentidos subjetivos só aparecerão com o compromisso pessoal, com o interesse em se posicionar ante o aprendido e defender e avançar por meio de posições próprias. Não existirá sentido subjetivo em uma atividade despersonalizada; portanto, o maior inimigo da aparição dos sentidos subjetivos na aprendizagem será a aprendizagem padronizada, centrada em exigências externas que impedem o aluno de tornar-se sujeito de seu percurso na aprendizagem.

Historicamente a aprendizagem escolar está vinculada a processos de aquisição de conhecimento com cunho memorístico e cognitivista, como salientaram Mitjáns Martínez e González Rey (2017, p. 93).

A educação escolar tem uma orientação essencialmente cognitivista e intelectualista que não considera o aluno sujeito de aprendizagem, nem o grupo em seus processos sociais. Domina um ensino centrado na memorização e na reprodução que não estimula os recursos intelectuais dos alunos.

O ensino de matemática tem priorizado os aspectos intelectuais e memorísticos dos alunos, como mostraram Medeiros e Muniz (2016) em estudo sobre as pesquisas relacionadas às dificuldades de aprendizagem matemática no Brasil. Há, hoje, grande ênfase nos resultados e nas técnicas de ensino de matemática, enquanto que o processo tem sido pouco analisado, sendo que este contém etapas e fatores importantes para compreensão da aprendizagem da matemática pela criança (MEDEIROS; MUNIZ, 2016). Nessa mesma direção González Rey (2006, p. 31) destaca que

A aprendizagem no cenário escolar está orientada mais pela transmissão de conhecimentos verdadeiros, do que pela discussão e reflexão dos conteúdos apresentados: aos alunos lhes é transmitido um mundo feito, não um mundo em processo de construção e representação, o que desmotiva a curiosidade e o interesse deles. Nesse processo, desestima-se o pensamento em prol da memória.

Assim, salientamos a importância do ambiente escolar para a aprendizagem dos alunos e seu desenvolvimento subjetivo. Nessa perspectiva, Mitjáns Martínez e González Rey (2017, p. 91) destacam que 


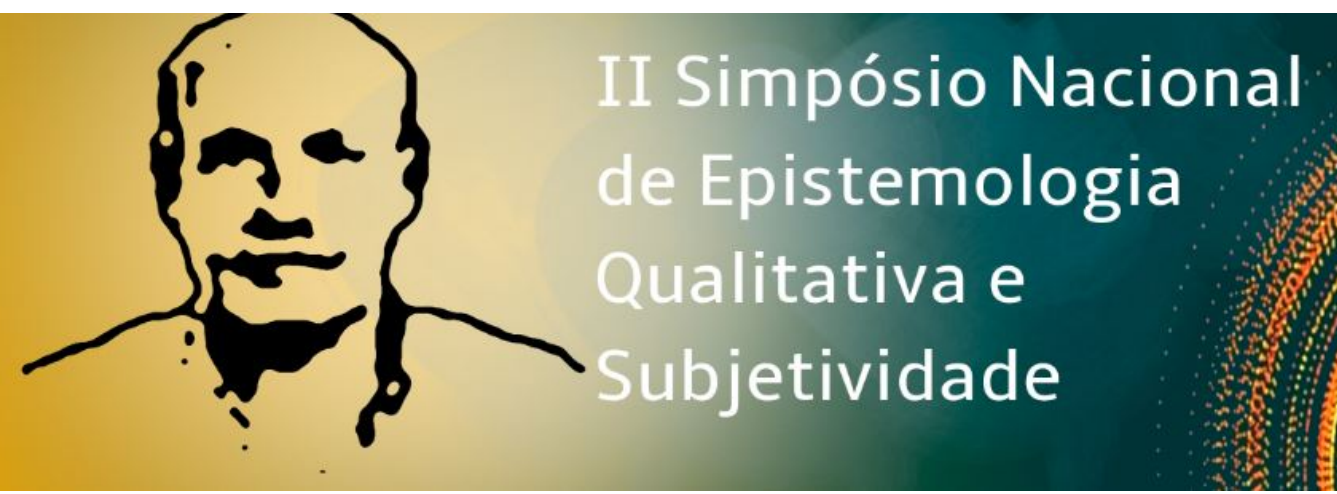

a subjetividade social, que domina a escola e suas diferentes práticas, é um aspecto essencial da qualidade da aprendizagem e do desenvolvimento dos alunos no ambiente escolar, desconstruindo de uma vez por todas a visão educativa individualista de que o sucesso do aprendiz depende unilateralmente da relação professor-aluno, da didática, da qualidade do docente e da capacidade dos estudantes, visão esta que descontextualiza tanto o professor quanto o aluno dos múltiplos espaços sociais e de suas formas hegemônicas de subjetividade social, nas quais se configuram suas subjetividades.

Logo, o espaço escolar é um espaço diferenciado, no qual o objetivo central é a aprendizagem dos conhecimentos historicamente construídos pela humanidade, por isso a importância de analisar como essa prática ocorre nesse espaço, essencialmente diferente dos espaços da família, igreja etc.

Para Tunes (2011, p. 9) "o aprender depende de uma vontade pessoal. Isso quer dizer que, mesmo sob a mira de uma arma uma pessoa pode recusar-se a aprender, fingir que aprende, aprender, mas depois esquecer ou, até mesmo, decidir aprender". Ou seja, a aprendizagem efetiva vai além dos processos memorísticos, abarcando processos emocionais, integrantes do sujeito.

Para González Rey (2011, p. 35) "só percebemos, refletimos e memorizamos aqueles aspectos que ganham sentido subjetivo dentro da configuração subjetiva que emerge no curso da experiência vivida que representa o momento vivo da personalidade na ação do sujeito". Logo, a qualidade das experiências vividas pelo sujeito são decisivas no processo de aprendizagem.

Como Tunes (2011) já destacou, ninguém pode ser forçado a aprender, pois a aprendizagem não é um momento racional. A criança em processo de aprendizagem não tem poder para definir os sentidos subjetivos produzidos no momento de aprendizagem, tão pouco como esses se configurarão nesse processo, pois estas são definidas de acordo com o arranjo sistêmico que envolve experiências vividas e o contexto da ação ou experiência atual. Nesse sentido, González Rey (2011, p. 36) ressalta que

não é o exercício da razão o que define as configurações subjetivas, ainda que as reflexões, representações e decisões do sujeito sejam sempre momentos desse sistema em desenvolvimento. Mas esses processos mais intencionais e racionais não 


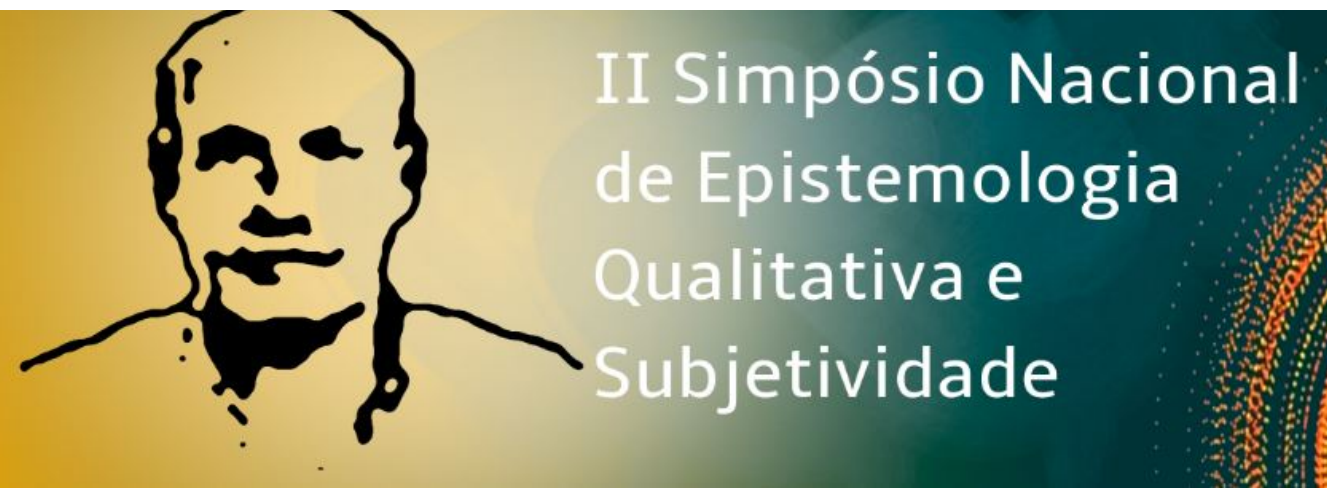

decidem o curso dessas configurações, mesmo que possam representar alternativas e rupturas em seu desenvolvimento.

Assim, destacamos a importância de observar a aprendizagem da criança em uma perspectiva da subjetividade, na qual a aprendizagem se dá por meio da produção de sentidos subjetivos, que se configuram no ato de aprender de tal forma que possibilita a produção de novos sentidos subjetivos, efetivando a aprendizagem. É importante destacar a importância do conceito de sentido subjetivo, já que é a partir da unidade simbólico-emocional que a criança produzirá conhecimento, possibilitando que este faça parte da sua subjetividade.

Nosso estudo tem como foco o processo de aprendizagem da criança, destacando a importância da participação desta como sujeito no seu processo de aprendizagem. Nessa perspectiva, Mitjáns Martínez e González Rey (2017) destacam três formas de expressão da aprendizagem que ocorrem no ambiente escolar, que se diferenciam pelos processos nelas envolvidos: "a aprendizagem reprodutiva-memorística, a aprendizagem compreensiva e a aprendizagem criativa” (MITJÁNS MARTÍNEZ; GONZÁLEZ REY, 2017, p. 62).

Aderimos aos conceitos trazidos por Mitjáns Martínez e González Rey (2017, p. 62) para falarmos de aprendizagem no espaço escolar, por isso destacamos a relevância de trazer esses conceitos:

\begin{abstract}
A aprendizagem reprodutiva-memorística caracteriza-se essencialmente por uma postura passiva do aprendiz em relação ao conhecimento, com predomínio de operações de assimilação mecânica dos conteúdos, em que as funções mnêmicas ocupam lugar central. Sem uma compreensão real da essência do estudado, o aprendiz tem dificuldade para utilizar esse conhecimento em situações novas e 'esquece' o aprendido com relativa facilidade. Esse tipo de aprendizagem caracteriza-se pela falta de interesse do aluno pelo que aprende e pela desvinculação da aprendizagem com sua vida pessoal. A aprendizagem compreensiva define-se essencialmente por uma postura ativa do aprendiz em relação ao conhecimento, tentando compreender sua essência e suas relações com outros conhecimentos ou experiências vividas. As operações reflexivas ocupam lugar central e o aprendiz, em função do grau de compreensão atingido, pode utilizar o aprendido em situações diferentes daquelas sobre as quais apoiou sua aprendizagem. A aprendizagem criativa é um tipo de aprendizagem no qual a criatividade tem uma presença marcante. Constitui a forma como a criatividade se expressa no processo de aprender e caracteriza-se pela configuração de três elementos: (1) a personalização da informação; (2) a confrontação com o conhecimento; e (3) a produção e geração de ideias próprias e 'novas' que vão além do conhecimento apresentado.
\end{abstract}

Para nós as formas de aprendizagem mais desejáveis são a compreensiva e a criativa, pois nestas além de uma efetiva participação da criança no seu processo de aprendizagem, 


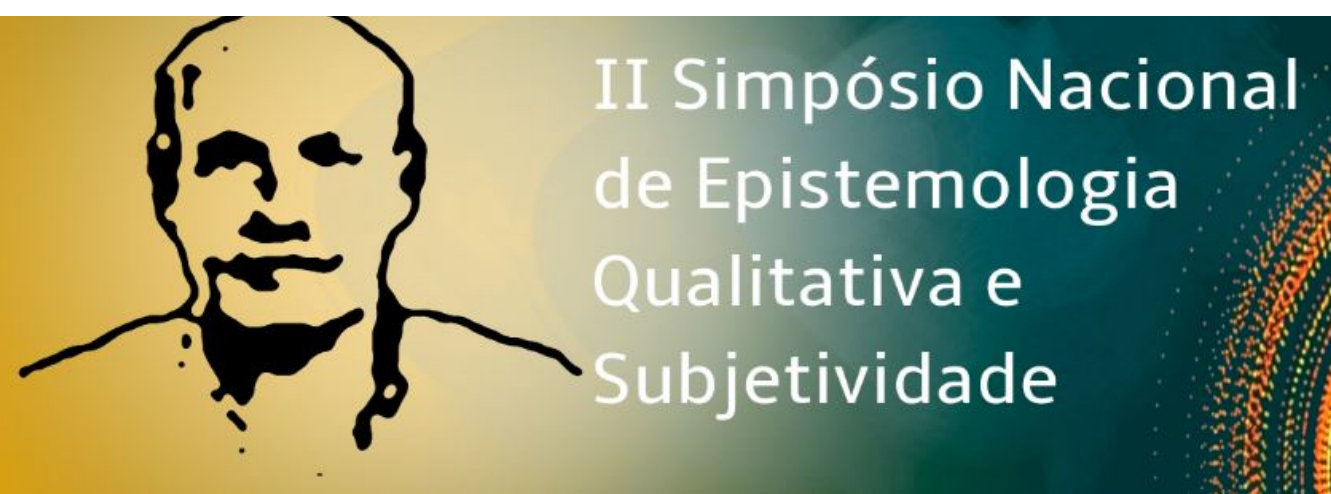

permite o desenvolvimento da subjetividade. Assim, a análise da aprendizagem feita por nós tem como prioridade o processo de aprendizagem e como desejável a aprendizagem compreensiva e criativa, pois possibilitará o desenvolvimento subjetivo.

Porém, fica uma pergunta, quais estratégias pedagógicas dentro da didática da matemática favorecem as aprendizagens compreensiva e criativa? Que metodologias no campo da matemática contribuem para uma aprendizagem que favoreça o desenvolvimento subjetivo?

\section{Referências}

BROUSSEAU, Guy. Os diferentes papéis do professor. In: PARRA, Cecília; SAIZ, Irma. (Orgs.). Didática da matemática: reflexões psicopedagógicas. Porto Alegre: Artmed, 2010.

GONZÁLEZ REY, Fernando. Sujeito e subjetividade. São Paulo: Thomson, 2005a.

GONZÁLEZ REY, Fernando. O valor heurístico da subjetividade na Investigação psicológica. In. GONZÁLEZ REY, Fernando. Subjetividade, complexidade e pesquisa em psicologia. São Paulo, Thomson, 2005b.

GONZÁLEZ REY, Fernando. O sujeito que aprende: desafios do desenvolvimento do tem da aprendizagem na psicologia e na prática pedagógica. In: TACCA, Maria Carmem V. R. Aprendizagem e trabalho pedagógico. Campinas: Alínea, 2006.

GONZÁLEZ REY, Fernando. Psicoterapia, subjetividade e pós-modernidade: uma aproximação histórico-cultural. São Paulo: Thomson, 2007.

GONZÁLEZ REY, Fernando. Subjetividade e Saúde: superando a clínica da patologia. São Paulo: Cortez, 2011.

GONZÁLEZ REY, Fernando. A configuração subjetiva dos processos psíquicos: avançando na compreensão da aprendizagem como produção subjetiva. In: MITJÁNS MARTINEZ, Alvertina; SCOZ, Beatriz Judith Lima; CASTANHO, Marisa Irene Siqueira (orgs.). Ensino e aprendizagem: a subjetividade em foco. Brasília: Liber Livros, 2012a. pp. 21-41.

GONZÁLEZ REY, Fernando. O social na psicologia e a psicologia social: a emergência do sujeito. Petrópolis: Vozes, 2012b. 


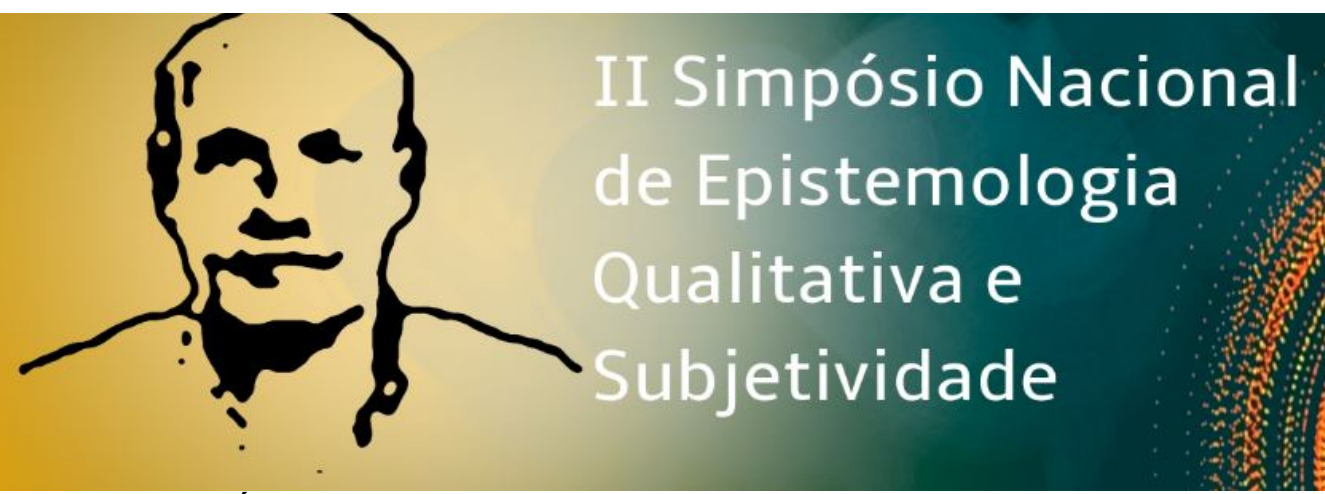

GONZÁLEZ REY, Fernando. Ideias e modelos teóricos na pesquisa construtivointerpretativa. In. In: MITJÁNS MARTÍNEZ, Albertina; NEUBERN, Mauricio; MORI, Valéria Deusdará. (Org.). Subjetividade Contemporânea: discussões epistemológicas e metodológicas. 1ed.Campinas: Alinea, 2014, pp. 13-34.

GONZÁLEZ REY, Fernando. Epistemologia Qualitativa e Subjetividade. In. I Simpósio Nacional de Epistemologia Qualitativa e Subjetividade. Conferência de abertura no Uniceub, Brasília, 2017.

GONZÁLEZ REY, Fernando; MITJÁNS MARTÍNEZ, Albertina. Subjetividade: Teoria, Epistemologia e Método. Campinas: Alínea, 2017.

GONZÁLEZ REY, Fernando; PATIÑO TORRES, José Fernando. La Epistemología Cualitativa y el estudio de la subjetividad en una perspectiva cultural-histórica: conversación con Fernando González Rey. Revista de Estudios Sociales, Bogotá, n. 60, 2017. pp. 120127.

MEDEIROS, Amanda Marina Andrade. A pesquisa no espaço escolar como possibilidade de formação de professores das séries iniciais para o ensino de matemática. Trabalho de Conclusão de Curso (Graduação em Pedagogia) - Faculdade de Educação, Universidade de Brasília. Brasília, 2006.

MEDEIROS, Amanda Marina Andrade. Afetos como construtores de uma práxis pedagógica no ensino-aprendizagem de matemática. Dissertação (Mestrado em Educação), Faculdade de Educação, Universidade de Brasília. Brasília, 2009.

MEDEIROS, Amanda Marina Andrade. A presença da afetividade na educação matemática dentro do ciberespaço: um estudo na formação de pedagogos. In: II Congresso Internacional TIC e Educação, 2012, Lisboa: Instituto de Educação da Universidade de Lisboa, 2012. pp. 2291-3006.

MEDEIROS, Amanda Marina Andrade. Mathematics Learning difficulty and affectivity: an investigation into postgraduate works in Brazil. In: 13th International Congress on Mathematical Education. Hamburg, 2016.

MEDEIROS, Amanda Marina Andrade; MUNIZ, Cristiano Alberto. Dificuldade de aprendizagem matemática e afetividade nos trabalhos de pós graduação no Brasil. In:

Encontro Nacional de Educação Matemática. São Paulo, 2016.

MITJÁNS MARTÍNEZ, Albertina. A Teoria da Subjetividade de González Rey: uma expressão do paradigma da complexidade na psicologia. In. GONZÁLEZ REY, Fernando.

Subjetividade, complexidade e pesquisa em psicologia. São Paulo, Thompson, 2005. 


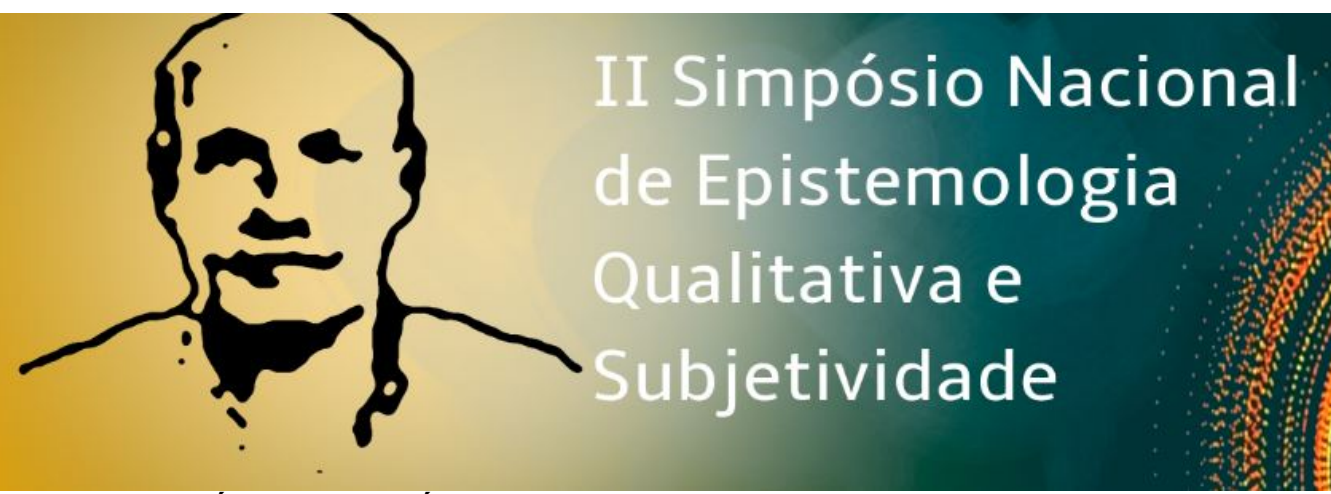

MITJÁNS MARTÍNEZ, Albertina. Aprendizagem criativa: desafios para a prática pedagógica. In: NUNES, Cláudio. Didática e formação de professores. Ijuí: Unijuí, 2012a, pp. 93-124.

MITJÁNS MARTÍNEZ, Albertina. Aprendizagem criativa: uma aprendizagem diferente. In: MITJÁNS MARTINEZ, Alvertina; SCOZ, Beatriz Judith Lima; CASTANHO, Marisa Irene Siqueira (Orgs.). Ensino e aprendizagem: a subjetividade em foco. Brasília: Liber Livros, 2012b. pp. 85-108.

MITJÁNS MARTÍNEZ, Albertina. Um dos desafios da pesquisa qualitativa: a criatividade do pesquisador. In: MITJÁNS MARTÍNEZ, Albertina; NEUBERN, Mauricio; MORI, Valéria Deusdará. (Org.). Subjetividade Contemporânea: discussões epistemológicas e metodológicas. 1ed.Campinas: Alinea, 2014, pp. 61-85.

MITJÁNS MARTÍNEZ, Albertina; GONZÁLEZ REY, Fernando. O subjetivo e o operacional na aprendizagem escolar. In: MITJÁNS MARTINEZ, Alvertina; SCOZ, Beatriz Judith Lima; CASTANHO, Marisa Irene Siqueira (orgs.). Ensino e aprendizagem: a subjetividade em foco. Brasília: Liber Livros, 2012. pp. 59-83

MITJÁNS MARTÍNEZ, Albertina; GONZÁLEZ REY, Fernando. Psicologia, educação e aprendizagem escolar: avançando na contribuição da leitura cultural histórica. São Paulo: Cortez, 2017.

MORIN, Edgar. O método I: a natureza da natureza. Lisboa: Publicações Europa-América, 1977.

MORIN, Edgar. Os sete saberes necessários à educação do futuro. São Paulo: Cortez, 2011.

MUNIZ, Cristiano Alberto. Mediação e conhecimento matemático. In: TACCA, Maria Carmem V. R. Aprendizagem e trabalho pedagógico. Campinas: Alínea, 2006.

MUNIZ, Cristiano Alberto. Brincar e jogar: enlaces teóricos e metodológicos no campo da educação matemática. Belo Horizonte: Autêntica Editora, 2010.

MUNIZ, Cristiano Alberto. As crianças que calculam: o ser matemático como sujeito produtor de sentidos subjetivos na aprendizagem. Relatório de pesquisa de pós-doutorado. Brasília: UnB, 2015.

ROSSATO, Maristela. O movimento da subjetividade no processo de superação das dificuldades de aprendizagem escolar. Tese (Doutorado em Educação), Faculdade de Educação, Universidade de Brasília, Brasília, 2009. 


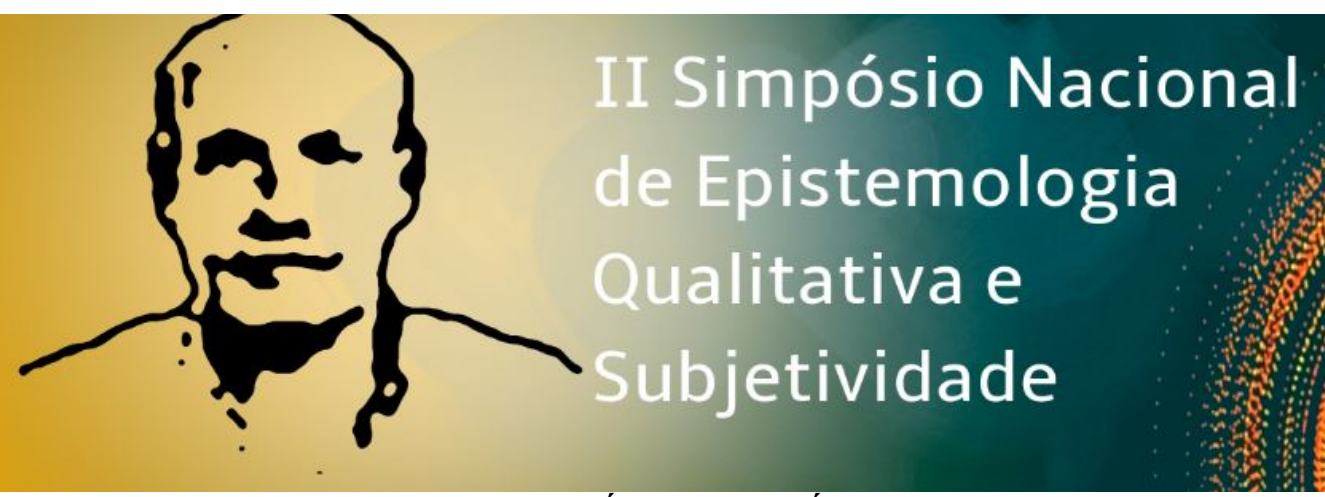

ROSSATO, Maristela; MITJÁNS MARTÍNEZ , Albertina. A superação das dificuldades de aprendizagem e as mudanças na subjetividade. In: TACCA, Carmen Villela Rosa e MITJÁNS MARTÍNEZ, Albertina. Possibilidades de Aprendizagem: ações pedagógicas para alunos com dificuldade e deficiência. Campinas: Alínea, 2011.p. 71 - 107.

ROSSATO, Maristela; MITJÁNS MARTÍNEZ, Albertina. Desenvolvimento da subjetividade: análise de histórias de superação das dificuldades de aprendizagem. Revista Semestral da Associação Brasileira de Psicologia Escolar e Educacional. São Paulo, Volume 17, Número 2, 2013, pp. 289-298.

TACCA, Maria Carmen Villela Rosa. Relação pedagógica e desenvolvimento da subjetividade. In: GONZÁLEZ REY, Fernando. Subjetividade, complexidade e pesquisa em psicologia. São Paulo, Thompson, 2005.

TACCA, Maria Carmen Villela Rosa; GONZÁLEZ REY, Fernando. Produção de sentido subjetivo: as singularidades dos alunos no processo de aprender. Psicologia Ciência e Profissão, Brasília, v. 1, n. 28, p.138-161, 2008.

TUNES, Elizabeth; BARTHOLO, Roberto. O trabalho pedagógico na escola inclusiva. In. TACCA, Maria Carmem Villela Rosa. Aprendizagem e trabalho pedagógico. Campinas: Alínea, 2006, p. 129 - 148.

TUNES, Elizabeth. Sem escola, sem documento. Rio de Janeiro: E-papers, 2011.

VIGOTSKI, Lev Semenovitch. Pensamento e linguagem. São Paulo: Martins Fontes, 1991.

VIGOTSKI. Obras escogidas: história del desarrollo de las funciones psíquicas superiores. Madrid: Visor, tomo III, 1995.

VIGOTSKI, Lev Semenovitch. Psicologia da arte. São Paulo: Martins Fontes, 1999.

VIGOTSKI, Lev Semionovich. Imaginação e criação na infância: ensaio psicológico. São Paulo: Ática, 2009a.

VIGOTSKI, Lev Semenovitch. A construção do pensamento e da linguagem. São Paulo: Martins Fontes, 2009b.

VIGOTSKI, Lev Semenovitch. Psicologia pedagógica. São Paulo: Martins Fontes, 2010. 